\title{
Cyclic behaviour of stone and brick masonry under uniaxial compressive loading
}

\author{
D.V. Oliveira $\cdot$ P.B. Lourenço $\cdot$ P. Roca
}

\begin{abstract}
An experimental research concerning the uniaxial compressive behaviour of stone and brick specimens, as well as masonry prisms, is presented. Local sandstone and clay brick materials were used in order to obtain results representative with respect to local constructions. Aiming at a comprehensive material description, a set of displacementcontrolled experiments were carried out, both under monotonic and cyclic compressive loading. The procedure adopted for testing is described and the results are discussed, namely material brittleness, intrinsic variability, energy dissipation and stiffness degradation.
\end{abstract}

Résumé Dans cet article une recherche expérimentale à propos du comportement en compression uniaxial de spécimens de pierre et de la brique, aussi bien que prismes de maçonnerie, est présenté. Grès et brique de l'argile locale ont été utilisés pour obtenir des résultats représentatifs en ce qui concerne les constructions locales. Avec l'objective de obtenir une description matérielle complète, un ensemble de tests contrôlé par déplacement a été emporté, sous chargement de compression monotonic et cyclique. La procédure adoptée pour tester est décrite et les résultats sont discutés, nommément la fragilité matérielle, variabilité intrinsèque des matériaux, dissipation d'énergie et déchéance de la raideur.

D.V. Oliveira · P.B. Lourenço

Universidade do Minho, Department of Civil Engineering, Guimarães, Portugal

P. Roca

Technical University of Catalunya, Department of Construction Engineering, Barcelona, Spain

\section{Introduction}

Laid dry or bonded with mortar, stones and bricks have been widely used as structural building materials since ancient times. Their use has improved and they have been applied in different ways throughout the centuries. This process has been so well succeeded that nowadays the majority of the world architectural heritage is composed of masonry constructions. However, this raises an important and complex issue, related to the evaluation of the structural safety of historical masonry constructions [1, 2]. Two main approaches have been usually followed to obtain comprehensive insight into the problem, namely experimental research and numerical modelling.

In spite of the need for reliable numerical analysis of historical masonry structures, only recently researchers have shown interest in the development and use of advanced constitutive models. This situation may be justified by two major reasons: the higher complexity of masonry behaviour, when compared to other building materials, such as concrete or steel, and the absence of a comprehensive experimental behavioural description of the material, required to calibrate any constitutive model. However, it has been shown that displacement-controlled experiments can be realistically carried out, aiming at a suitable characterization of the structural response of masonry and its components and, thus, making available the necessary properties for the use of advanced numerical models [3-5]. Consequently, the acquirement of material data necessary for advanced nonlinear numerical modelling is inevitably a key issue.

Until few years ago, importance was only given to the evaluation of the ultimate load. Due to that, post-peak behaviour of masonry is still insufficiently characterized. This gap in knowledge constituted an extra encouragement to the execution of the research presented in this paper. 
The experimental uniaxial behaviour, obtained under displacement-controlled tests, is usually characterized by the establishment of a stress-strain (or stress-displacement) diagram, in which the most important features that characterize the behaviour of the material should be included, namely the complete pre-peak branch, the peak load and significant part of the post peak branch. In the case of cyclic experiments, features as strength and stiffness degradation as well as energy dissipation should be also characterized. An important feature, experimentally observed and common to all frictional materials, is the occurrence of softening after peak. Furthermore, for materials that display a very brittle behaviour, the use of the axial displacement as the control variable under tensile/compressive loading may not be enough to ensure that post-peak behaviour can be captured.

In this paper, a set of experimental uniaxial compressive tests, performed under monotonic and cyclic loading, carried out on stone and brick specimens and prisms is presented, being the main results discussed in detail. All the experiments were carried out at the Structural Technology Laboratory of the Technical University of Catalunya, Barcelona, in cooperation with Universidade do Minho, Portugal.

\section{Uniaxial compressive behaviour of stone specimens and prisms}

A locally available sandstone, known as "Montjuic stone", was selected as being a common construction material used to build stone constructions in Barcelona. The stones were previously cut and delivered into the laboratory in small prismatic pieces $\left(200 \times 200 \times 100 \mathrm{~mm}^{3}\right)$. Macroscopically, the sandstone presents a homogeneous surface and a very small grain size.

\subsection{Compressive tests on stone specimens}

In order to ensure a uniform stress distribution in the center of a specimen, a height/diameter ratio between two and three and a diameter preferably not less than $50 \mathrm{~mm}$ are recommended, if standard lateral deformation restraining steel platens are used [6]. Moreover, it is known that the height/diameter ratio highly influences the peak strength, and the later decreases as the former increases [7]. In the present work, cylindrical specimens $\left(\varnothing 50 \times 120 \mathrm{~mm}^{2}\right)$ were used, resulting in a height/diameter ratio $(\mathrm{h} / \mathrm{d})$ of 2.4 , for which a uniaxial stress state is expected in the center of specimens.

The stone specimens (SS) are denoted by the stone number and by the specimen number. Therefore, the reference SS2.1 represents the first specimen obtained from stone $n^{\circ} 2$. In order to ensure correct sampling, specimens were extracted randomly from different stones.
A closed-loop servo-controlled testing machine was used to perform the tests. A circumferential linear variable differential transformer (lvdt) placed at the specimen mid-height and three axial lvdts placed between the machine platens were used as displacement measurement transducers. The applied force was measured by means of the machine load cell. All specimens were tested with their natural water content (air dry conditions).

Preliminary tests performed under axial displacement control showed that a specific control technique had to be used in order to obtain the post-peak behaviour under cyclic loading. Therefore, tests were carried out under the following control variables [8]:

- Axial displacement control for a low applied load;

- Force control during unloading;

- Circumferential displacement control in general.

In order to compute the values of Young's modulus and Poisson's ratio, two stone specimens (SS3.1 and SS4.1) were tested with three double electric resistance strain gauge rosettes attached to each specimen, equally spaced around the perimeter and placed at mid-height. The characterization of specimen's behaviour in terms of its elastic properties, the evolution of Young's modulus $(E)$, Poisson's ratio $(v)$ and volumetric strain $\left(\varepsilon_{\mathrm{vol}}\right)$ is presented in Fig. 1 for specimen SS3.1, where $E_{\mathrm{lvdt}}$ and $E_{\mathrm{sg}}$ represent the computed Young's modulus using lvdt and strain gauge data, respectively. In order to represent different quantities in the same diagram, different scales were used which are not represented in Fig. 1.

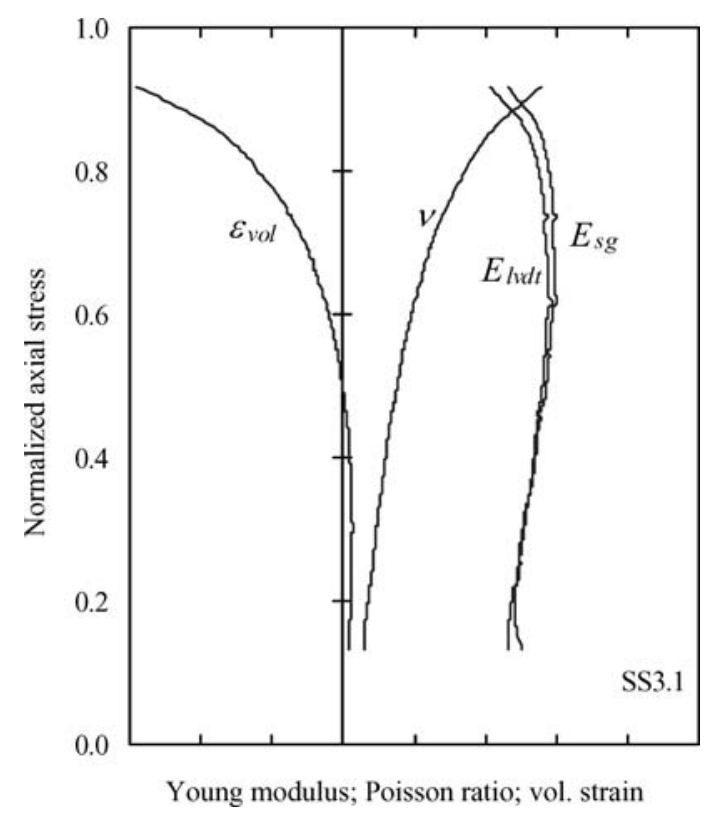

Fig. 1 Typical variation of Young's modulus $\left(E_{\mathrm{lvdt}}\right.$ and $\left.E_{\mathrm{sg}}\right)$, Poisson's ratio $(\nu)$ and volumetric strain $\left(\varepsilon_{\mathrm{vol}}\right)$ with stress level for stone specimens (specimen SS3.1 and different units in the abscissa axis). 
By increasing the load, the closure of existing microcracks and voids produced an increase in Young's modulus. At higher stress levels, Young's modulus started to decrease due to the initiation of macrocracks, whereas Poisson's ratio increased continually with the load. This behaviour can be explained by microcrack closure, for lower stress levels, and the initiation/propagation of cracks, for higher stress levels. This means that variations in $E$ and $v$ are clearly related to the fracture of the specimen [9].

Initially, a slight volume reduction took place, caused by axial compression, being followed by an important volume increase due to crack formation. For half of the peak load, there was no volume variation, which means that crack formation took place for relatively lower stresses. The very large positive volume variation for higher stresses in compression can be explained by splitting fracture. This phenomenon of positive volume variation in compression is known as dilatancy. For a load near half of the ultimate load, Poisson's ratio equals his theoretical maximum elastic value, equal to 0.5 . This means that dilatancy has a major importance in the behaviour of the specimen and that microcracking starts at relatively low stress levels. The formation of multiple shear bands took place when the post-peak region was reached and its development seemed to be the cause of failure, associated with large volume increase of the specimen, see Fig. 2.

Figure 1 also shows also that $E$ and $v$ were greatly affected by the nonlinearities in the stone's behaviour, which renders difficult to define the elastic properties from uniaxial test results. The procedure defined by ASTM [10] allows the use of several methods employed in engineering practice, consequence of the difficulties described above. Following the ASTM proposal, Young's modulus can also be defined as the average slope of the linear portion of the stress-strain diagram. For the specimens tested, the straight-line portion is located in the [30\%-60\%] stress range; the values of $E$ obtained within this range, using linear least square regressions, are presented in Table 1. The elastic modulus calculated using strain gauges is greater than the value obtained using the

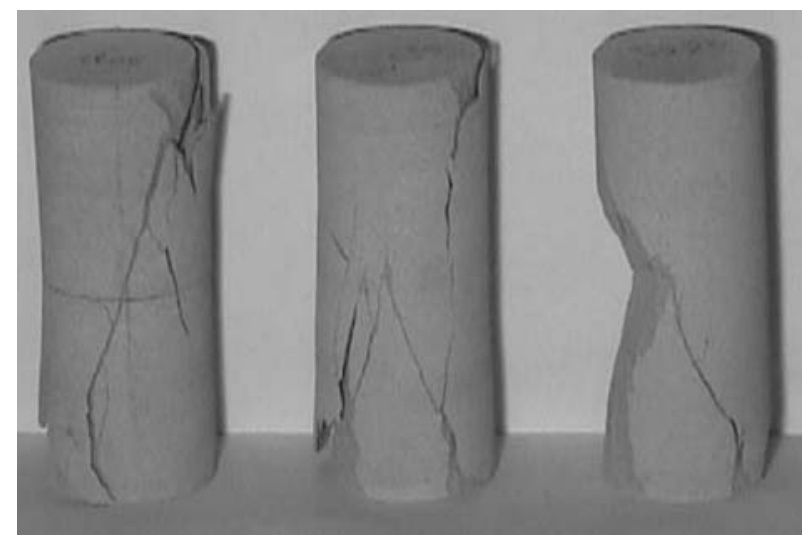

Fig. 2 Typical observed failure modes of stone specimens.
Table 1 Young's modulus defined in the [30\%-60\%] stress range for the specimens SS3.1 and SS4.1

\begin{tabular}{lll}
\hline Specimen & $E_{\text {lvdt }}[\mathrm{GPa}]$ & $E_{\mathrm{sg}}[\mathrm{GPa}]$ \\
\hline SS3.1 & 13.68 & 13.86 \\
SS4.1 & 17.71 & 19.20 \\
\hline
\end{tabular}

data from lvdts (the axial lvdt measurements could be influenced by the platens movement), but differences are not significant (less than 9\%), which seems to indicate that data obtained by means of lvdts may be used to evaluate Young's modulus in specimens tested without strain gauges.

Following the test procedure afore-mentioned, four monotonic tests and six cyclic tests were performed in order to characterize the complete stress-strain diagram (based on data acquired via lvdts), as well as the cyclic behaviour of sandstone. Figure 3 illustrates typical stress-strain diagrams obtained under monotonic and cyclic loading. All the remaining diagrams can be found in [8]. The diagrams exhibit the well known bedding down effect, characterized by an initial adjustment between the specimen and the machine platens. As expected, pre-peak behaviour was easily followed, but the post-peak branch, where the load decreased in a very unsmooth way, showed to be unstable and could only be characterized with great effort. The first macroscopical cracks

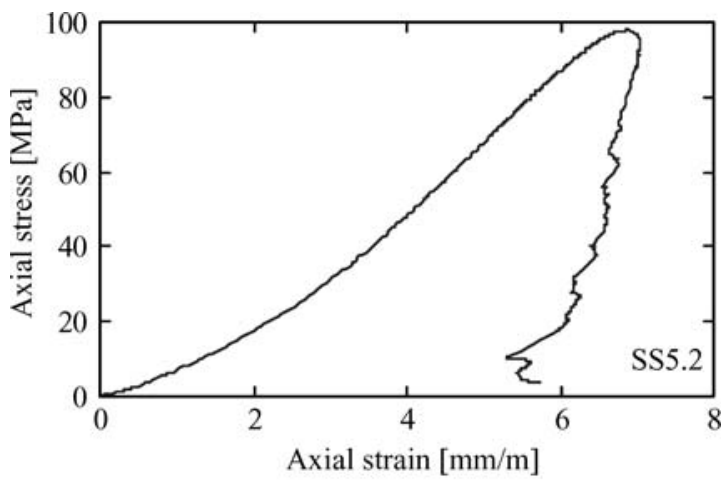

(a)

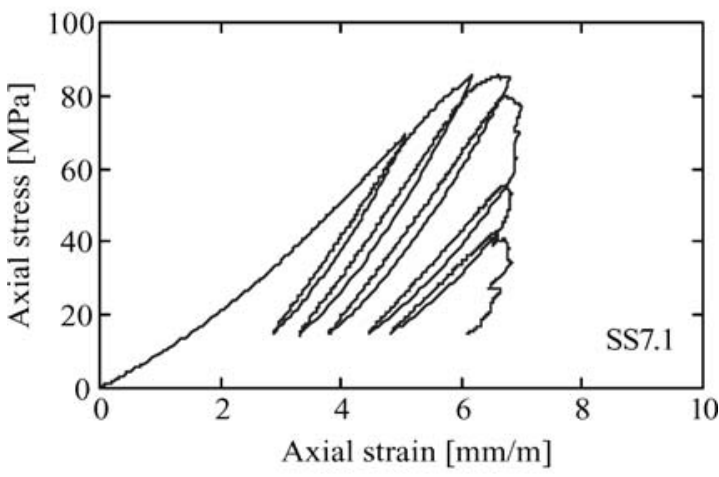

(b)

Fig. 3 Typical stress-strain diagrams of stone specimens tested under uniaxial compression: (a) monotonic and (b) cyclic loading. 
Table 2 Young's modulus and compressive strength of stone specimens tested under uniaxial compressive loading

\begin{tabular}{lcl}
\hline Specimen & $E_{30-60}[\mathrm{GPa}]$ & $\sigma_{\text {peak }}[\mathrm{MPa}]$ \\
\hline SS2.2 & 9.50 & 61.1 \\
SS2.3 & 10.46 & 68.6 \\
SS3.2 & 12.64 & 70.4 \\
SS4.2 & 15.54 & 84.5 \\
SS5.1 & 17.49 & 93.9 \\
SS5.2 & 17.89 & 98.0 \\
SS6.1 & 19.56 & 86.6 \\
SS6.2 & 20.30 & 87.8 \\
SS7.1 & 15.62 & 85.4 \\
SS8.1 & 16.49 & 90.2 \\
Average & 15.55 & 82.7 \\
CV $(\%)$ & 22.26 & 13.7 \\
\hline
\end{tabular}

were visible only for a load very close to the peak one, starting at the extreme ends and progressing through the entire specimen.

The Young's modulus of all stone specimens, evaluated within the [30\%-60\%] stress range, is showed in Table 2, as well as the compressive strength (CV is the coefficient of variation). The average value shows that the uniaxial compressive strength of the stone is rather high. Furthermore, the maximum Young's modulus value is greater than the double of the minimum value obtained. The differences found between the several tested specimens in terms of compressive strength and Young's modulus indicate that the intrinsic variability of these properties is an important issue that should be considered when dealing with natural stone structures.

Regarding the cyclic behaviour of the stone specimens, unloading-reloading cycles were done both during pre-peak and post-peak. In the pre-peak region, a slight increase of stiffness occurred, which is in agreement with the monotonic results obtained from tests using strain gauges. On the other hand, a monotonic decrease of stiffness in the post-peak region was observed. This decrease is naturally related with the progressive damage growth suffered by the specimen.

With the purpose of highlighting the enormous importance of an appropriate choice of the control technique, the relationship between axial and circumferential length variations, computed for the specimen SS11.1, is showed in Fig. 4. Pre-peak is characterized by a remarkable variation in axial length when compared with the circumferential one. As a result, this branch can be obtained under common axial displacement control. Fig. 4 also shows that, for this particular material, post-peak behaviour cannot be described if axial displacement control is used, due to the plateau exhibited. Therefore, after the peak the axial displacement control must be substituted by a monotonic increasing signal in order to obtain the complete stress-strain diagram. A possible control seems to be the adopted circumferential displacement control.

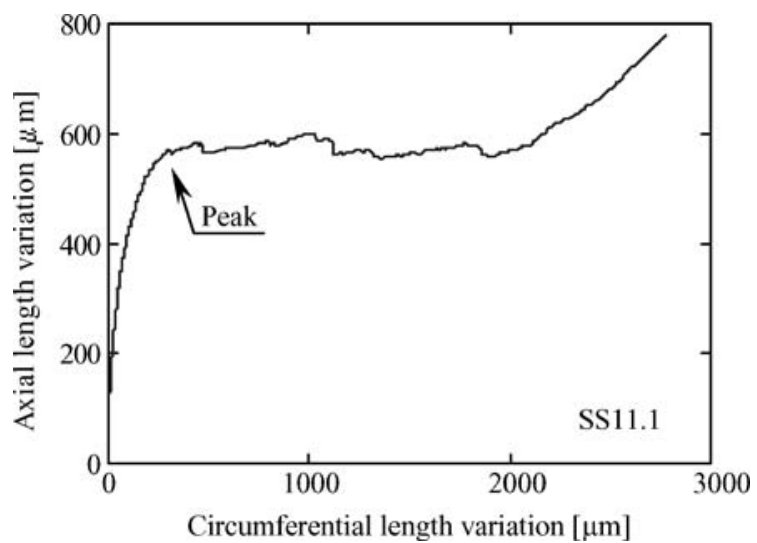

Fig. 4 Typical relationship between axial and circumferential length variations (stone specimen SS11.1).

\subsection{Compressive tests on stone prisms}

Additionally, a set of experimental tests on stone prisms was carried out under uniaxial compressive loading. The stones were laid dry to replicate dry joint stone masonry, i.e., the prisms were simply built by the superposition of prismatic stone pieces.

It was decided to perform uniaxial compressive tests on two different geometries, with different slenderness ratios. According to the available stones, two prisms made of three $100 \times 200 \times 100 \mathrm{~mm}^{3}$ pieces $(\mathrm{h} / \mathrm{d}=3)$ and other two prisms made of four $200 \times 200 \times 100 \mathrm{~mm}^{3}$ pieces $(\mathrm{h} / \mathrm{d}=2)$ were built and tested. The adopted $\mathrm{h} / \mathrm{d}$ ratios allowed uniaxial compressive behaviour at the center of the prisms. The terminology adopted to denote the prisms was based on the number of pieces used. Prisms denoted as SP1 and SP2 were prisms made of three pieces each and prisms made of four pieces were denoted as SP3 and SP4.

The stone prisms were tested in a testing machine with a load capacity of $5000 \mathrm{kN}$ and able to work under axial force or displacement control. Three axial lvdts placed between the machine platens were used as displacement measurement transducers. The applied load was measured by means of the machine load cell. The four experiments were performed under axial displacement control (in general) and force control (during unloading). Figure 5 presents a typical stress-strain diagram of the tested stone prisms. The usual initial adjustment between the prism and the machine platens is visible. Again, the pre-peak branch was easily followed. All prisms showed a reasonable linear behaviour almost until peak, and then failed just after reaching peak load, exhibiting pronounced brittle behaviour. As a result, post-peak could not be characterized.

As before, the Young's modulus of the four prisms was evaluated within the [30\%-60\%] stress range. Table 3 summarizes the Young's modulus and the compressive strength values of the four stone prisms. If a comparison between these 
Table 3 Young's modulus and compressive strength of the stone prisms

\begin{tabular}{cll}
\hline Specimen & $E_{30-60}[\mathrm{GPa}]$ & $\sigma_{\text {peak }}[\mathrm{MPa}]$ \\
\hline 3 stones & & \\
SP1 & 16.21 & 75.2 \\
SP2 & 14.27 & 49.3 \\
4 stones & & \\
SP3 & 13.75 & 42.1 \\
SP4 & 14.96 & 61.9 \\
Average & 14.80 & 57.12 \\
\hline
\end{tabular}

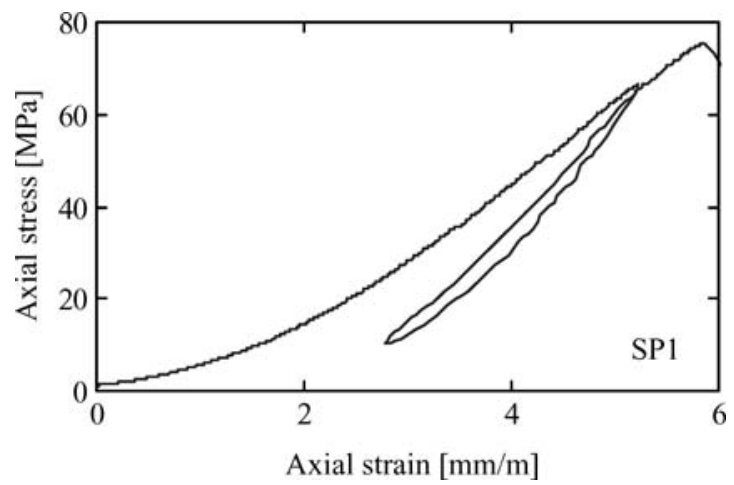

Fig. 5 Typical stress-strain diagram of the stone prisms tested under cyclic loading.

results and results concerning monolithic stone specimens is established, no significant differences regarding the Young's modulus are found (the difference in average values is smaller than 5\%). However, important differences with respect to the peak strength are effectively found (with a reduction in the average strength of $30 \%$ ). The use of several stone pieces in one prism, associated with the wide scattering, is an important factor that can originate lower maximum strength values in comparison to the monolithic stone specimens. Indeed, a reduction of strength in only one of the stone pieces is enough to reduce the overall strength of the prism. The use of assembled stone pieces reduces the scatter of the results and the compressive strength [11], however, the moderate number of specimens tested in the present research program does not allow any statistical analysis. Being the compression failure controlled by mode I behaviour, the discontinuity between stone pieces is likely to result in stress concentrations in a few contact points, leading to the premature formation of vertical cracks in the stones, thus originating failure for a load lower than the values achieved with the stone specimens.

These observations are significant for an improved knowledge on the mechanical response of dry masonry. However, more research is still needed in order to fully understand the behaviour of this historical material.

\section{Uniaxial compressive behaviour of brick specimens and prisms}

An experimental research, similar to the one developed for stone masonry presented in Section 2, was carried out on the mechanical behaviour of clay brick masonry. The bricks selected are common clay, solid bricks produced in the region of Barcelona for cladding purposes; they are red in color and present average dimensions of $285 \times 130 \times 50 \mathrm{~mm}^{3}$. This type of brick was selected because of its similitude with traditional, manually manufactured ones widely used in the recent past as a structural material. A detailed characterization of the mechanical properties of these bricks has not been available till the beginning of this research.

\subsection{Compressive tests on brick specimens}

Due to the production processes, bricks can exhibit different mechanical properties in the vertical and horizontal directions. Additionally, the microstructure of the brick is highly influenced by the firing temperature. Considering that masonry structures have usually moderate to low thickness, the flatwise $(50 \mathrm{~mm})$ and lengthwise $(285 \mathrm{~mm})$ directions are clearly the most important to be studied. Therefore, uniaxial compressive tests on prismatic brick specimens, in the flatwise and lengthwise directions were performed. No tests were performed in the widthwise direction $(130 \mathrm{~mm})$.

The problem of adopting an appropriate slenderness ratio for the specimens has already been addressed. To ensure a suitable height/width ratio, prisms of $40 \times 40 \times 120 \mathrm{~mm}^{3}$ were adopted $(h / d=3)$. The vertical specimens (VPBS $n$, flatwise direction) were made from three aligned cubes of $40 \times 40 \times 40 \mathrm{~mm}^{3}$ with no material between them, according to RILEM [12] and other researchers [13], while the horizontal specimens (HPBSn, lengthwise direction) were cut in single pieces.

The brick specimens were tested using the testing equipment described in Section 2.1, under axial displacement control, whereas relative displacements were measured by means of three axial lvdts placed between the machine platens. The aim of the test was to acquire the Young's modulus and the peak strength values for each direction. This control technique has not allowed insight into the post-peak behaviour. Table $4 \mathrm{a}$ and $4 \mathrm{~b}$ summarize the obtained results. Young's modulus was computed in the [30\%-70\%] stress range of the peak load because all stress-strain diagrams exhibited linear behaviour within this range. On average, the vertical specimens exhibited a higher elastic modulus (an increase of 22\%), with small coefficients of variation found for both directions. Regarding the compressive strength, vertical strength is, on average, $11 \%$ higher than the horizontal strength due to the anisotropy inherent to the extrusion process. However, higher coefficients of variation were found, which seems to indicate 
Table 4 Young's modulus and ultimate strength of vertical and horizontal prismatic brick specimens

\begin{tabular}{lccc}
\hline Specimen & & $E_{30-70}[\mathrm{GPa}]$ & $\sigma_{\text {peak }}[\mathrm{MPa}]$ \\
\hline \multirow{4}{*}{ Vertical direction } & (a) Vertical prismatic & \\
& VPBS1 & 11.86 & 52.7 \\
& VPBS2 & 12.84 & 56.2 \\
& VPBS3 & 12.86 & 62.7 \\
Average & VPBS4 & 13.43 & 55.7 \\
CV (\%) & & 12.75 & 56.8 \\
& & 4.43 & 6.4 \\
Horizontal direction & HPBS1 & 10.51 & 44.8 \\
& HPBS2 & 10.94 & 59.5 \\
& HPBS3 & 10.47 & 54.1 \\
Average & HPBS4 & 9.89 & 45.5 \\
CV (\%) & & 10.45 & 51.0 \\
\hline
\end{tabular}

an important scatter in the peak strength values, especially in the horizontal direction, probably due to the alignment of shrinkage or firing cracks.

The former tests showed that capturing post-peak behaviour requires a more sophisticated control technique than measuring the axial deformation by means of lvdts. The encouraging results from the use of the circumferential displacement control with stone specimens led to the adoption of the same control technique for brick specimens. In this way, cylindrical specimens formed by three aligned cylindrical pieces $\left(\varnothing 50 \times 40 \mathrm{~mm}^{2}\right)$ and denoted by VCBS $n$ were used, resulting in a height/width ratio of 2.4. Only vertical cylindrical brick specimens were tested because this is the usual loading direction of masonry.

The testing procedures adopted for cylindrical brick specimens were similar to the ones used on the stone specimens, namely control variables and measurement equipment. As done before with the stones, two brick specimens (VCBS1 and VCBS2) were previously tested under monotonic loading, using three double electric resistance strain gauges rosettes. The simultaneous use of the axial lvdts and strain gauges allowed comparisons between the two computed strains.

The evolution of the tangent values of Young's modulus $(E)$, Poisson's ratio $(v)$ and volumetric strain $\left(\varepsilon_{\mathrm{vol}}\right)$ is shown in Fig. 6. The Young's modulus was calculated using both lvdt $\left(E_{\mathrm{lvdt}}\right)$ and strain-gauge $\left(E_{\mathrm{sg}}\right)$ data. Once more, the typical adjustment between the machine platens and the specimen is visible in the initial branch of the diagram. But, as expected, in the diagrams computed with strain-gauge data, such accommodation does not appear. The Poisson's ratio increases continuously with the applied load and equals 0.5 for a very high load, between $80 \%$ and $90 \%$ of the ultimate load, corresponding to a volumetric strain equal to zero. Young's modulus remains more or less constant under load increase and

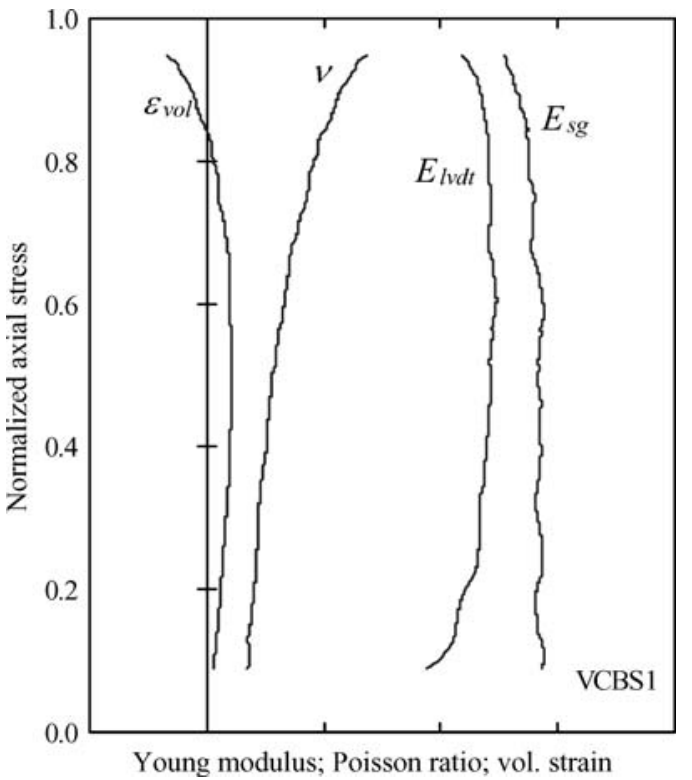

Fig. 6 Typical variation of Young's modulus $\left(E_{\mathrm{lvdt}}\right.$ and $\left.E_{\mathrm{sg}}\right)$, Poisson's ratio $(v)$ and volumetric strain $\left(\varepsilon_{\mathrm{vol}}\right)$ with stress level for brick specimens (specimen VCBS1 and different units in the abscissa axis).

presents higher values if calculated with strain-gauge data. A possible reason for this fact is related with the stiffness of the glue used to fix the strain gauges. Tests done on bricks have showed that the stiffness measured with strain gauges may be increased due to glue penetration into the brick [13]. For porous and less stiff materials, the glue might have a considerable local influence, which can increase with the porosity of the material. On the other hand, the introduction of the horizontal dry joints on the brick specimens might have influenced the measurement of Young's modulus by means of lvdts, leading to a slightly underestimation. Considering that Young's modulus is computed in the approximately linear region of the stress-strain diagram, the values of $E$ computed in the $[30 \%-70 \%]$ stress range, using linear least square regressions, are presented in Table 5. No remarkable differences are found between the two specimens. In spite of the lower values of $E$ obtained with lvdts, these values can be considered accurate enough for the purpose of numerical calculations.

In order to acquire knowledge regarding post-peak behaviour, it was decided to perform advanced tests on brick specimens, using the circumferential displacement control technique. According to the procedure described in Section 2.1, three monotonic tests and four cyclic tests were carried

Table 5 Young's modulus defined in the [30\%-70\%] stress range for the specimens VCBS1 and VCBS2

\begin{tabular}{lll}
\hline Specimen & $E_{\mathrm{lvdt}}[\mathrm{GPa}]$ & $E_{\mathrm{sg}}[\mathrm{GPa}]$ \\
\hline VCBS1 & 12.11 & 14.24 \\
$\mathrm{VCBS} 2$ & 13.29 & 15.07 \\
\hline
\end{tabular}




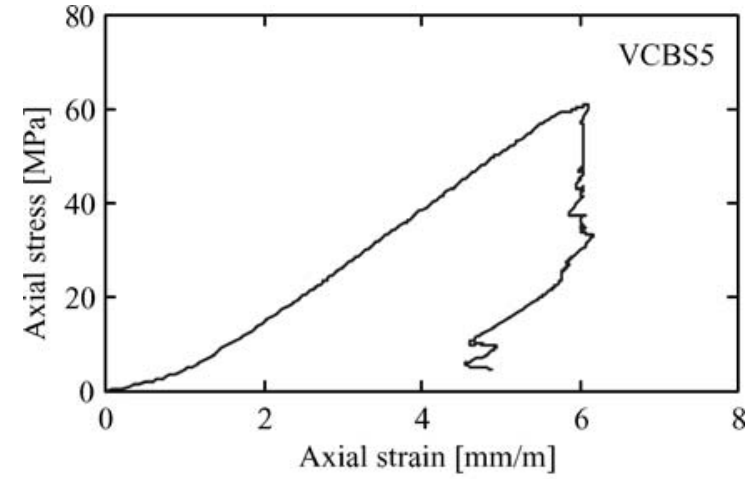

(a)

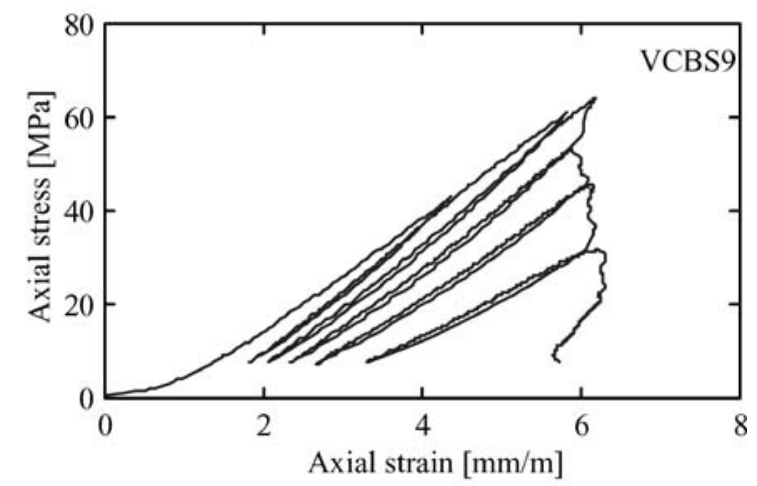

(b)

Fig. 7 Typical stress-strain diagrams of brick specimens tested under uniaxial compression: (a) monotonic and (b) cyclic loading.

out. Typical stress-strain diagrams are illustrated in Fig. 7 , but all of them can be found in [8]. The diagrams are characterized by an initial typical curve, a linear and stable pre-peak branch, quite similar in all specimens, and an unstable postpeak behaviour. Near the peak, macroscopic crack initiation in the brick cylinders took place close to the platens. The brittleness of the material rendered tests very unstable, making post-peak behaviour extremely difficult to characterize.

Table 6 presents the Young's modulus computed in the [30\%-70\%] stress range and the compressive strength, for all specimens tested. It can be observed that no important differences regarding either Young's modulus or the ultimate

Table 6 Young's modulus and compressive strength of brick specimens tested under uniaxial compressive loading.

\begin{tabular}{lcc}
\hline Specimen & $E_{30-70}[\mathrm{GPa}]$ & $\sigma_{\text {peak }}[\mathrm{MPa}]$ \\
\hline VCBS3 & 9.50 & 61.1 \\
VCBS4 & 10.46 & 68.6 \\
VCBS5 & 12.64 & 70.4 \\
VCBS6 & 15.54 & 84.5 \\
VCBS7 & 17.49 & 93.9 \\
VCBS8 & 17.89 & 98.0 \\
VCBS9 & 19.56 & 86.6 \\
Average & 12.42 & 61.7 \\
CV $(\%)$ & 9.57 & 9.3 \\
\hline
\end{tabular}

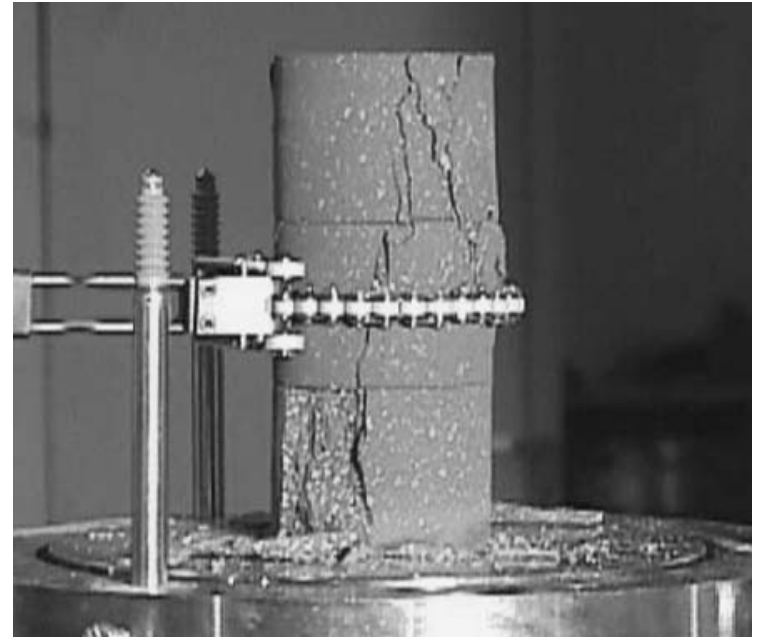

Fig. 8 Typical observed failure mode of cylindrical brick specimens.

strength were found (CV lower than $10 \%$ in both cases). Moreover, Tables 4 and 6 show that the brick strength in the vertical direction presents very similar values. Additionally, if Table 5 is considered together with the two aforementioned tables, it is possible to observe that also the Young's modulus exhibits a relatively constant value, which seems to indicate that the average Young's modulus and ultimate strength values from Table 6 are rather reliable.

As happened with the prismatic specimens, the three aligned cylinders behaved as a continuous specimen in the sense that cracks ran through the cylinders with continuity. Most of the specimens presented diagonal cracking, from the bottom up to the top, where failure occurred through the development of shear bands, as illustrated in Fig. 8.

\subsection{Compressive tests on brick masonry prisms}

In order to characterize the behaviour of brick masonry under cyclic loading, four stacked bond prisms, of five bricks each, were tested. The main purpose was to examine the effects of brick and mortar properties on the strength and deformation characteristics of masonry prisms.

Usually, mortar presents a softer behaviour whereas clay bricks exhibit a stiffer behaviour. The mechanical properties of masonry depend on the characteristics of the component materials and on the construction conditions, since workmanship effects can have a large influence on the mechanical properties of masonry. It is clearly known that under uniaxial compression, mortar tends to expand laterally more than brick, but due to the continuity between them, ensured by cohesion and friction, mortar is confined laterally by the bricks. Thus, shear stresses, developed at the mortar-brick interface, produce a triaxial compressive stress state in the mortar and bilateral horizontal tension coupled with vertical compression in the brick, causing failure by the development of cracks in the bricks, parallel to the loading direction [14]. 
The stacked bond prisms were built in accordance to RILEM recommendations [15]. The bricks used in this study are similar to the ones described in Section 3.1, while the mortar was made from a pre-mix, based on Portland cement and fine aggregates $(0-2 \mathrm{~mm})$. Four prisms consisting of five stacked bricks were built, whereas mortar joints were kept with a uniform thickness of about $10 \mathrm{~mm}$, resulting in prisms of $285 \times 130 \times 280 \mathrm{~mm}^{3}$ with a slenderness ratio $(\mathrm{h} / \mathrm{d})$ of 2.15. This ratio allowed uniaxial compressive behaviour at the center of the prisms.

The experimental average mortar compressive strength was $5.5 \mathrm{MPa}$ but this value should be regarded as merely indicative since conditions of mortar curing inside the prism and inside the mould are necessarily different. The prisms, as well as the mortar specimens, were stored and cured outside the laboratory in order to simulate real curing conditions.

The brick prisms were tested under force and displacement control, according to the procedure described in Section 2.2, used to test the stone prisms. Here, it was decided to perform several unloading-reloading branches in order to check the properties related to cyclic behaviour, such as stiffness degradation and hysteretic energy dissipation, since a more ductile behaviour during post-peak was expected.

The compressive strength of each prism is displayed in Table 7, where it can be observed that all prisms present similar strength values, and a typical stress-strain diagram of the prisms is presented in Fig. 9. Apart from the initial adjustment between the prism and the machine platens, all stress-strain

Table 7 Compressive strength of the brick masonry prisms.

\begin{tabular}{ll}
\hline Prism & $\sigma_{\text {peak }}[\mathrm{MPa}]$ \\
\hline BP1 & 28.9 \\
BP2 & 28.8 \\
BP3 & 28.2 \\
BP4 & 28.3 \\
Average & 28.6 \\
CV $(\%)$ & $1.1 \%$ \\
\hline
\end{tabular}

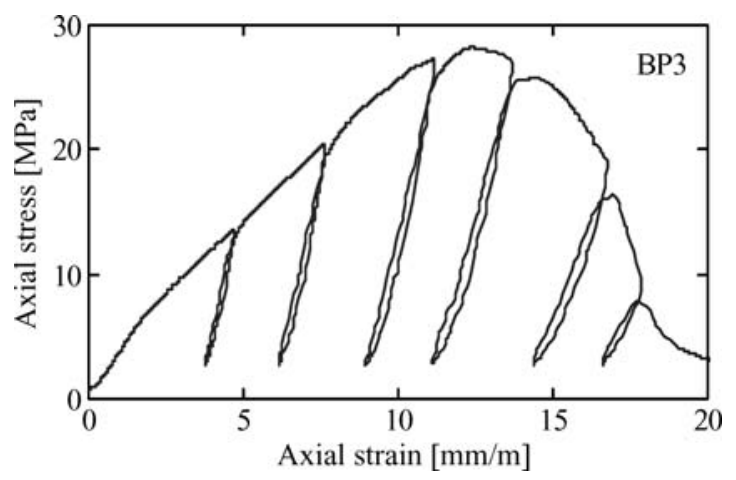

Fig. 9 Typical stress-strain diagram of the brick masonry prisms tested under cyclic loading.

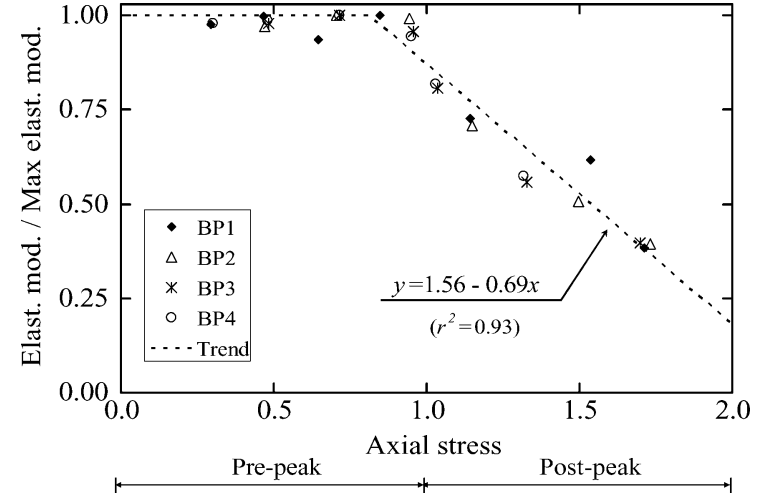

Fig. 10 Normalized elastic modulus of the reloading branches as a function of the normalized axial stress, for all brick prisms.

curves exhibited a pre-peak bilinear behaviour. An initial linear branch is followed by another linear branch up to near the peak, with lower stiffness and greater strain. Transition between these two different slopes is located between $6 \mathrm{MPa}$ and $10 \mathrm{MPa}$ (approximately $21 \%$ and $35 \%$ of the peak load, respectively) and it defines the beginning of the nonlinear behaviour of masonry. The beginning of brick cracking and mortar nonlinearities are the likely origin of this behaviour.

Two other relevant aspects are clearly visible from the analysis of Table 7 and Fig. 9. The average compressive strength of masonry is much higher than the mortar strength, as expected. The key factor is that the mortar joint between bricks was subjected to a triaxial compressive stress state. Results from triaxial tests have shown that mortar behaviour is dependent on confining pressure as well as on mortar type, and that ultimate axial stress increases with confining pressure [16]. A second aspect has to do with the ductility observed from the diagrams of Fig. 9, when compared with stress-strain curves obtained for brick specimens, where a very fragile structural behaviour was found. From this comparison, it can be concluded that mortar has a preponderant influence on prism deformation, where a reduction of the peak strength was compensated by a less fragile post-peak behaviour. As reported by other researchers [17], it is clear that the compressive strength of masonry is highly influenced by the characteristics of its individual components, brick and mortar.

The evolution of stiffness degradation was also investigated. The evolution of the elastic modulus associated to each reloading branch as a function of the axial stress normalized by the peak stress is graphically illustrated in Fig. 10. It can be observed that the stiffness of the reloading branches of all prisms presented relatively close values for a same stress level. During pre-peak, stiffness remained relatively constant. In opposition, during post-peak the slope of the reloading branches suffered an important decrease, due to damage caused to the material. The post-peak stiffness degradation may be considered linearly dependent on the applied stress level. 


\section{Conclusions}

This paper presents an experimental study aiming at the mechanical characterization of historical building materials, consisting of several stone and brick specimens as well as prisms, tested under monotonic and cyclic compressive loading. The work aimed at providing detailed information on the response of stone and brick masonry. Among other purposes, the information obtained can be useful for the formulation and calibration of advanced material constitutive laws, e.g. $[18,19]$.

The stone studied is characterized by a high compressive strength and a very pronounced fragile behaviour. The cyclic tests performed show that stiffness degradation occurs especially during the post-peak domain.

The small differences obtained between lvdts and strain gauges measurements enable the assessment of the Young's modulus by means of axial lvdts, both for stone and brick specimens.

The results obtained from brick specimens showed also a high compressive strength and a brittle behaviour. On the other hand, even if the brick specimens were made of three aligned cylinders, they behaved as whole specimens, since the cracks ran continuously through the cylinders. Considering average values, no significant differences were found between prismatic and cylindrical specimens, in terms of Young's modulus and peak strength values. Regarding the brick prisms, its average compressive strength value was much higher than the mortar compressive strength, but less than the average compressive strength of the bricks tested separately. The lower compressive strength of the brick prisms was compensated by a more stable post-peak behaviour.

The Young's modulus computed for the stone specimens and for the dry-stone masonry prisms presented very similar average values. However, the scatter concerning the mechanical properties constitutes an important issue in the sense that a significant decrease of strength takes place when shifting from stone specimens to stone masonry (in terms of average values). This subject should be further studied since existing design codes, e.g. EC6 [20], do not take stacked dry-stone masonry into consideration.

The brittle behaviour exhibited by stone and brick specimens evidenced that post-peak regime cannot be adequately analysed using axial displacement control. A more advanced technique based on a monotonic increasing control signal, namely circumferential displacement control, had to be used.

Finally, the results presented in this paper undoubtedly show that the intrinsic variability of the mechanical properties of natural stone and brick masonry is an important issue that should be kept in mind when dealing with historical building materials.

\section{References}

1. Oliveira CS (2003) Seismic Vulnerability of Historical Constructions: A Contribution. Bulletin of Earthquake Engineering 1:3782 .

2. Augusti G, Ciampoli M (2000) Heritage buildings and seismic reliability. Progress in Structural Engineering and Materials 2(2):225237.

3. CUR Rots JG, (ed) (1997) Structural masonry: An experimental/numerical basis for practical design rules, (Balkema, Rotterdam).

4. Lourenço PB (1998) Experimental and numerical issues in the modelling of the mechanical behavior of masonry. In P. Roca et al. editors Structural Analysis of Historical Constructions II CIMNE Barcelona 57-91.

5. Pegon P, Pinto AV, Géradin M (2001) Numerical modelling of stoneblock monumental structures. Computers \& Structures 79(2225):2165-2181.

6. Fairhurst CE, Hudson JA (1999) Draft ISRM suggested method for the complete stress-strain curve for intact rock in uniaxial compression. Int J Rock Mech and Mining Sciences 36:279289.

7. Neville AM (1995) Properties of concrete. (Pitman Publishing London).

8. Oliveira DV (2003) Experimental and numerical analysis of blocky masonry structures under cyclic loading. (PhD. Dissertation Universidade do Minho Guimarães) Available from www.civil.uminho.pt/masonry.

9. Li C, Prikryl R, Nordlund E (1998) The stress-strain behaviour of rock material related to fracture under compression. Engineering Geology 49:293-302.

10. The American Society for Testing and Materials (2004) Standard test method for elastic moduli of intact rock core specimens in uniaxial compression. (Annual Book of ASTM Standards Section 4) 04.08:D3148-96.

11. Mosteller F, Rourke R (1993) Sturdy statistics (nonparametrics) and order statistics. Addison-Wesley Reading (Massachusetts USA).

12. RILEM (1994) Technical recommendations for the testing and use of constructions materials: LUMA1 - Compressive strength of masonry units (Chapman \& Hall, UK).

13. Binda L, Tiraboschi C, Mirabella Roberti G, Baronio G, Cardani G (1996) Measuring masonry material properties: detailed results from an extensive experimental research Part I: Tests on masonry components. (Report 5.1 Politecnico di Milano).

14. Vermeltfoort AT (2005) Brick-mortar interaction in masonry under compression. (PhD. Dissertation, Eindhoven University of Technology Eindhoven).

15. RILEM (1994) Technical recommendations for the testing and use of constructions materials: LUMB 1 -Compressive strength of small walls and prisms. (Chapman \& Hall, UK).

16. McNary WS, Abrams $P$ (1985) Mechanics of masonry in compression. J. Struct Eng ASCE 111(4):857-870.

17. Binda L, Tiraboschi C, Mirabella Roberti G, Baronio G, Cardani G (1996) Measuring masonry material properties: Detailed results from an extensive experimental research, Part II: Tests on masonry specimens. (Report 5.1 Politecnico di Milano).

18. Lourenço PB, Rots JG (1997) A multi-surface interface model for the analysis of masonry structures. J Eng Mech ASCE 123(7):660668.

19. Oliveira DV, Lourenço PB (2004) Implementation and validation of a constitutive model for the cyclic behaviour of interface elements. Computers and Structures 82:1451-1461.

20. Eurocode 6: (1995) Design of masonry structures. ENV 1996-11:1995 CEN (Brussels Belgium). 